\title{
Effects of placement point of background music on shopping website
}

\author{
Chien-Jung Lai* and Chia-Chi Chiang \\ Department of Distribution Management, National Chin-Yi University of Technology, No.57,Sec.2, Chung-Shan \\ Rd., Taiping Dist., Taichung City, Taiwan
}

\begin{abstract}
Consumer on-line behaviors are more important than ever due to highly growth of on-line shopping. The purposes of this study were to design placement methods of background music for shopping website and examine the effect on browsers' emotional and cognitive response. Three placement points of background music during the browsing, i.e. 2 min., 4 min., and $6 \mathrm{~min}$. from the start of browsing were considered for entry points. Both browsing without music (no music) and browsing with constant music volume (full music) were treated as control groups. Participants' emotional state, approach-avoidance behavior intention, and action to adjust music volume were collected. Results showed that participants had a higher level of pleasure, arousal and approach behavior intention for the three placement points than for no music and full music. Most of the participants for full music (5/6) adjusted the background music. Only 16.7\% (3/18) participants for other levels turn off the background music. The results indicate that playing background music after the start of browsing is benefit for on-line shopping atmosphere. It is inappropriate to place background music at the start of browsing shopping website. The marketer must manipulated placement methods of background music for a web store carefully.
\end{abstract}

Keywords: Background music, shopping website, placement

\section{Introduction}

Empirical work has examined specific atmospheric cues and their effects on shopper response in brickand-mortar environment. As in brick-and-mortar environments, atmospheric cues have been posited to influence consumers on the web [8]. Online retailing has attracted a great deal of attention in recent years due to the rapid developing of the Internet. Some researchers have been already begun to call for more systematic research by using established retailing and consumer behavior theories. Dailey [5] defined web atmospherics as "the conscious designing of web environments to create positive effects in user in order to increase favorable consumer responses (e.g., site revisiting, browsing, etc.)". Eroglu et al. [8] classified web atmospheric cues into high task-relevant cues (i.e., descriptions of the merchandise, the price, etc.) and low task-relevant cues (i.e., the colors, typestyles and fonts, music and sounds, etc.). These cues form the atmosphere of a web site. Bitner argued that music is a critical ambient condition of the servicescape and that music influences people's emotions and physiological feelings, and mood [6]. Various structure characteristics of music, such as time (rhythm, tempo, and phrasing), pitch (melody, keys, mode, and harmony), and texture (timbre, orchestration, and volume), influence consumer response and behavior [3]. There have been a number of studies that investigate the effect of background music on the physical environment in the interest of various research fields, for example, advertising, retail/manufacturing, and ergonomics $[4,7]$.

As a natural departure from the stimuli present in a traditional retail store, the online retail environment can only be manipulated by visual and auditory cues. In the past, research of online store focused on the design of website structure and interface from visual stimulus, few carried on the discussion from the auditory stimulus. Recently many websites place background music to attract browsers' attention. Some researches start to study the effect of background

*Corresponding author. E-mail: laicj@ncut.edu.tw 
music on consumer response [2]. These researches assumed the existence of background music. However, this premise is not necessarily tenable. Browser masters the broadcast of background music of online website. He or she may stop broadcast momentarily. Then the effects of background music have no way to begin with. To discuss the effect of background music of online store, it is necessary to allow browsers to accept the existence of background music first.

Background music is always played from the beginning of a website browsing. The main purposes of this study are to design placement points of background music for the duration of web browsing and examine the effects of these placements on browsers' emotional and cognitive response.

\section{Methods}

This study proposed three placement points of background music during the browsing on shopping website. 2 min., $4 \mathrm{~min}$., and $6 \mathrm{~min}$. from the start of browsing are considered for entry points of background music. Both browsing without music (no music) and browsing with constant music volume (full music) were treated as control groups. The maximum volume is set to be $60 \mathrm{db}$. Fig. 1 shows the conceptual framework of the placement methods. A betweensubject experiment was performed to explore the effects of these placements on browsers' response. An online book store was designed and served as the context of this experiment. There were home page, merchandise page and purchase merchandise page on the website. The home page consisted of 20 books with five categories which were introduced for participant to browse. The merchandise page described the detail information such as author, price, publisher and abstracts for each book. The classical concerto from Vivaldi's "The four seasons, chapter one, spring" was used for background music. It is an allegro of fast tempo 120 BPM. 30 participants were recruited and were asked to browse the website and then complete a purchase task. Variable amount of time to browse was allowed as long as the participants want. Mehrabian and Russell's 12-item semantic differential scale [1] with 7-point Likert scale was employed as the emotional response measure. The level of agreement with 4 statements on a 7-point Likert scale was collected to indicate participants' approach-avoidance behavior intention. The actions for a participant to adjust music volume or to turn music off were also observed and recorded.

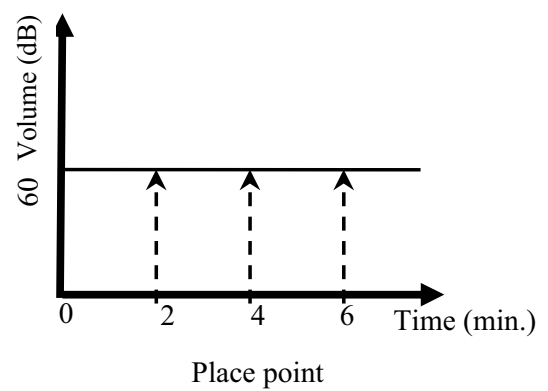

Fig. 1 The conceptual framework of the placement points for background music

\section{Results}

Table 1 shows the means and standard deviations of emotional response and approach-avoidance behavior intention under each point of the placement. Descriptive statistics demonstrated that participants had a higher level of pleasure and arousal for $2 \mathrm{~min}$., $4 \mathrm{~min}$., and $6 \mathrm{~min}$. than for no music and full music. For the pleasure, all levels are greater than average pleasure mood (scale=4). For the arousal, all levels are less than average arousal mood. The lowest average arousal mood is 2.92 for non-music. All placement methods had greater approach behavior intention than for none music (None) and with constant music volume (Full). However, analysis of variance (ANOVA) showed there was no statistical difference.

Table 1 Descriptive statistics of emotional response, approachavoidance intention, and frequency to adjust music volume under points of placement.

\begin{tabular}{|c|c|c|c|c|c|c|c|c|c|}
\hline \multirow{3}{*}{$\begin{array}{l}\text { Point } \\
\text { of } \\
\text { place } \\
\text { ment }\end{array}$} & & \multicolumn{4}{|c|}{ Emotional states } & \multirow{2}{*}{\multicolumn{2}{|c|}{$\begin{array}{l}\text { Approach- } \\
\text { avoidance } \\
\text { behavior } \\
\text { intention }\end{array}$}} & \multirow{2}{*}{\multicolumn{2}{|c|}{$\begin{array}{l}\text { Frequency to } \\
\text { adjust music } \\
\text { volume }\end{array}$}} \\
\hline & \multicolumn{3}{|c|}{ Pleasure } & \multicolumn{2}{|c|}{ Arousal } & & & & \\
\hline & & Mean & S.D. & Mean & S.D. & Mean & S.D. & $\begin{array}{l}\text { Ad- } \\
\text { justed }\end{array}$ & $\begin{array}{l}\text { Unad- } \\
\text { justed }\end{array}$ \\
\hline $\begin{array}{l}2 \\
\min .\end{array}$ & 6 & 4.92 & 0.89 & 3.58 & 0.87 & 5.00 & 1.14 & 1 & 5 \\
\hline $\begin{array}{l}4 \\
\min .\end{array}$ & 6 & 4.95 & 0.83 & 3.69 & 0.85 & 5.08 & 0.52 & 1 & 5 \\
\hline $\begin{array}{l}6 \\
\min .\end{array}$ & 6 & 5.14 & 1.11 & 3.50 & 0.69 & 4.96 & 1.49 & 1 & 5 \\
\hline Full & 6 & 4.42 & 0.87 & 3.17 & 1.06 & 4.33 & 0.86 & 5 & 1 \\
\hline None & 6 & 4.72 & 0.64 & 2.92 & 0.57 & 4.56 & 1.47 & None & None \\
\hline
\end{tabular}


The frequencies to adjust music volume or to turn music off were also summarized in Table 1 . It was found that most of the participants for full music $(5 / 6)$ adjusted the background music. Only $16.7 \%(3 / 18)$ participants for other levels turn off the background music.

\section{Discussion}

The purpose of this study was to investigate suitable placement point of background music, which can affect browsers' behavior. The results found that participants had less pleasure and arousal for full music than for other placement points of background music during online store browsing. It was also found that $83.3 \%$ of the participants for full music adjusted the background music. Full music, i.e. browsing with constant music volume could be treated as a distractor while browsing an online shopping store. The processing of music will consume the mental resource from the beginning of browsing, the overloading of resources will lead to impaired browsing task. However, playing background music after browsing for a certain period could induce higher pleasure, arousal and approach behavior intention. The results suggest that it is inappropriate to place background music at the start of browsing shopping website. The marketer must manipulated placement points of background music for a web store carefully.

The results of this study support the belief that browser's behavior is affected by a retail environment factor like background music. Playing background music after the start of browsing is benefit for on-line shopping atmosphere. Though the relationship between the measures have not examined clearly in the present study, it can be a good model for further related studies.

\section{Acknowledgement}

This research was funded by the National Science Council of Republic of China under contract no. NSC 99-2221-E-167-020-MY2.

\section{References}

[1] Bitner, M. J., Servicescape: The impact of physical surroundings on consumers and employees, Journal of Marketing, vol.56, pp.57-71, 1992.

[2] Bruner II, G.C., Music, mood, and marketing. Journal of Marketing, vol.54, no.4, pp.94-104, 1990.

[3] Herrington, J. D., \& Capella, L.M.., Practical application of music in service settings. Journal of Services Marketing, vol.8, no.3, pp.50-65, 1994.

[4] Oakes, S., The influence of the musicscape within service environments. Journal of Services Marketing, vol.14, no.7, pp.539-550, 2000.

[5] Dailey, L., 2004. Navigational web atmospherics explaining the influence of restrictive navigation cues, Journal of Business Research, Vol. 57, pp. 795-803.

[6] Eroglu, S. A., Machleit, K. A., and Davis, L. M., 2001. Atmospheric qualities of online retailing: A conceptual model and implications. Journal of Business Research, Vol. 54, No. 2, pp. 177-184

[7] Mehrabian, A. and Russel, J. A.., 1974. An Approach to Environmental Psychology. MIT Press, Cambridge, MA.

[8] Wu, C. S., Cheng, F. F. and Yen, D. C., 2008. The atmospheric factors of online storefront environment design: An empirical experiment in Taiwan. Information \& Management, Vol. 45, pp. 493-498. 